\title{
Influência da adubação orgânica no desempenho inicial de diferentes cultivares de gergelim cultivadas em Crato/CE
}

A semente de gergelim é matéria prima para obtenção de óleo de qualidade, sendo utilizada no Nordeste brasileiro em virtude da boa adaptabilidade às características edafoclimática, constituindo, além disso, como alternativa de renda. A semente é um dos insumos mais importantes e tem um papel fundamental na produção agrícola, sendo que seu desempenho é um fator essencial para a obtenção de um estande desejável de plantas, contribuindo significativamente no rendimento da cultura. Contudo, o conhecimento da fisiologia das sementes é limitado. Dentre os testes de avaliação da qualidade fisiológica de sementes, a germinação é o método tradicionalmente empregado para determinar o potencial máximo de germinação de um lote de sementes. Nesse sentido, o presente trabalho teve como objetivo selecionar cultivares com maiores índices de emergência e vigor, quando submetidas a diferentes percentagens de substrato bovino, comparando o potencial de duas cultivares melhoradas e duas crioulas. Foi utilizado o delineamento experimental inteiramente casualizado - DIC, em esquema fatorial de substrato bovino, comparando o potencial de duas cultivares melhoradas e duas crioulas. Foi utilizado o delineamento experimental inteiramente casualizado - DIC, em esquema fatorial emergência final (\%EF), número de dias para estabilizar a emergência (NDE) e Índice de velocidade de emergência (IVE). Os dados foram submetidos à análise de variância para avaliar o efeito significativo, por meio do teste de comparação de médias Tukey a $F(p \leq 0,01)$ e $F(p \leq 0,05)$ de probabilidade para o fator qualitativo. Os dados quantitativos foram testados por regressão, escolhendo-se o modelo com maior coeficiente de determinação $\left(R^{2}\right)$, empregando o programa SISVAR. De acordo com os resultados, a cultivar crioula Barros apresentou maior eficiência nos seguintes quesitos analisados: IVE, NDE, \%EF, \%El, In.EF e In. El. As cultivares BRS Seda e Crioula Barros foram equivalentes na precocidade.

Palavras-chave: Sesamum indicum L.; Cutivares crioulas; Substrato; Emergência; Precocidade.

\section{Influence of organic fertilization on the initial performance of different sesame cultivars cultivated in Crato/CE}

\begin{abstract}
Sesame seed is a raw material for obtaining quality oil, being used in Northeast Brazil due to its good adaptability to edaphoclimatic characteristics, constituting, in addition, as an alternative income. The seed is one of the most important inputs and has a fundamental role in agricultural production, and its performance is an essential factor for obtaining a desirable plant stand, contributing significantly to the crop yield. However, knowledge of seed physiology is limited. Among the tests to evaluate the physiological quality of seeds, germination is the method traditionally used to determine the maximum germination potential of a seed lot. In this sense, the present work aimed to select cultivars with higher rates of emergence and vigor, when submitted to different percentages of bovine substrate, comparing the potential of two improved cultivars and two creoles. A completely randomized experimental design - DIC was used, in submitted to different percentages of bovine substrate, comparing the potential of two improved cultivars and two creoles. A completely randomized experimental design - DIC was used, in
a $4 \times 5$ factorial scheme, with four replications. The variables analyzed were the initial emergency index (In.EI), final emergency index (In.EF), percentage of initial emergency (\% EI), percentage of final emergency (\% EF), number of days to stabilize the emergency (NDE) and Emergency Speed Index (IVE). The data were subjected to analysis of variance to assess the significant effect, using the Tukey means comparison test to $F(p \leq 0.01)$ and $F(p \leq 0.05)$ of probability for the qualitative factor. Quantitative data were tested by regression, choosing the model with the highest coefficient of determination $\left(R^{2}\right)$, using the SISVAR program. According to the results, the Creole cultivar Barros showed greater efficiency in the following items analyzed: IVE, NDE, $\% \mathrm{EF}, \% \mathrm{El}, \mathrm{In} . \mathrm{EF}$ and In. El. The cultivars BRS Seda and creole Barros were equivalent in precocity.
\end{abstract}

Keywords: Sesamum indicum L.; Cutivares creole; Substrate; Emergency; Precocity.

\section{Topic: Ciências do Solo}

Reviewed anonymously in the process of blind peer.
Received: 02/02/2021

Approved: 25/02/2021
Gilberto Saraiva Tavares Filho (D) Universidade Federal do Vale do São Francisco, Brasil

http://lattes.cnpq.br/0502160177022205 http:///attes.cnpq.br/05021601770222 gilfilho753@hotmail.com

Sammy Sidney Rocha Matias (iD) Universidade Estadual do Piauí, Brasil http://lattes.cnpq.br/7571737375393995 http://orcid.org/0000-0002-5729-3284 ymmsa2001@yahoo.com.br

Renan Castro Lins (iD

Universidade Federal do Cariri, Brasil http://lattes.cnpq.br/6507976920673481 http://orcid.org/0000-0002-5215-5771 renancastro94@hotmail.com
Nágela Maria Henrique Mascarenhas (iD) Universidade Federal de Campina Grande, Brasil

http://lattes.cnpq.br/0971881401771176 http://orcid.org/0000-0001-9059-3695 eng.nagelamaria@gmail.com

Cícero Aparecido Ferreira Araújo (iD Universidade Federal do Cariri, Brasil http://lattes.cnpq.br/5887446046810771 http://orcid.org/0000-0002-0285-5630 nino1178@live.com

\section{Mailson Gonçalves Gregorio}

Universidade Federal de Campina Grande, Brasil

http://lattes.cnpq.br/4059274514503706 http://orcid.org/0000-0002-6960-7973 gregoriomailson@gmail.com
Airton Gonçalves de Oliveira (D) Universidade Federal de Campina Grande, Brasil

http://lattes.cnpq.br/4285867711243914 http://orcid.org/0000-0001-7150-0123 airtonifce@yahoo.com.br

Raimundo Calixto Martins Rodrigues (iD) Universidade Federal de Campina Grande, Brasil

http://lattes.cnpq.br/5197092679324068 http://orcid.org/0000-0001-8437-7857 calixto_80@hotmail.com

\section{Samuel Ferreira Pontes (iD)}

Universidade Federal do Piauí, Brasil http://lattes.cnpq.br/5268797301695901 http://orcid.org/0000-0001-7696-3629

samuellpontes@outlook.com
Raissa Rachel Salustriano da Silva Matos Universidade Federal do Maranhão, Brasil http://lattes.cnpq.br/0720581765268326 http://orcid.org/0000-0002-8908-2297 raissasalustriano@yahoo.com.br

Referencing this:

TAVARES FILHO, G. S.; MATIAS, S. S. R.; LINS, R. C.; MASCARENHAS, N. M. H.; ARAÚJO, C. A. F.; GREGORIO, M. G.; OLIVEIRA, A. G.; RODRIGUES, R. C. M.; PONTES, S. F.; MATOS, R. R. S. S.. Influência da adubação orgânica no desempenho inicial de diferentes cultivares de gergelim cultivadas em Crato/CE. Revista Ibero Americana de Ciências Ambientais, v.12, n.2, p.11-18, 2021. DOI:

http://doi.org/10.6008/CBPC2179-6858.2021.002.0002 


\section{INTRODUÇÃO}

O gergelim (Sesamum indicum L.) é a mais antiga oleaginosa conhecida, tendo como centro de origem à África, onde se concentra a maioria das espécies silvestres do gênero Sesamum (SOUSA et al., 2017). No Brasil, é plantado tradicionalmente na região Nordeste, pois se constitui uma alternativa de grande importância socioeconômica para a região, por ser de fácil cultivo, possuir tolerância relativamente alta a estiagem e, principalmente, por gerar renda e trabalho, sendo fonte de alimento para pequenos e médios produtores (FURTADO et al., 2017). Tais características acabam por transformar essa cultura em uma excelente opção de diversificação agrícola com grande potencial econômico (DIAS et al., 2017).

As sementes de gergelim são amplamente utilizadas na alimentação e diante de novas descobertas vem ganhando nova forma de uso com destaque para o óleo extraído das sementes que é de excelente qualidade, o que amplia as possibilidades econômicas da utilização do gergelim. Com o recente incentivo do governo Federal, em utilizar o biodiesel na matriz energética nacional, as oleaginosas surgem como fonte de energia renovável com a finalidade de preservação do meio ambiente (SOUSA et al., 2017).

A semente é um dos insumos mais importantes e tem um papel fundamental na produção agrícola (NÓBREGA et al., 2020), sendo que seu desempenho é um fator essencial para a obtenção de um estande desejável de plantas, contribuindo significativamente no rendimento da cultura. Dentre os testes de avaliação da qualidade fisiológica de sementes, a germinação é o método tradicionalmente empregado para determinar o potencial máximo de germinação de um lote de sementes (SILVA et al., 2016).

A adubação orgânica não só incrementa a produtividade, mas também produz plantas com características qualitativas melhores que as cultivadas exclusivamente com adubos minerais podendo, portanto, exercer influência sobre a qualidade nutricional (CARVALHO et al., 2017). A queda da produtividade é consideravelmente acentuada em virtude de baixos índices de germinação, acarretando perdas capazes de desmotivar os produtores regionais. Portanto, é de grande importância um prévio conhecimento das características das sementes de cada variedade, sendo essas determinantes na produtividade final da respectiva cultura.

Com essa finalidade, esse trabalho tem por objetivo selecionar cultivares com maiores índices de emergência e vigor, quando submetidas a diferentes percentagens de substrato bovino, comparando o potencial de duas cultivares melhoradas e duas crioulas.

\section{MATERIAIS E MÉTODOS}

O trabalho foi desenvolvido no mês de março de 2019 no Centro de Ciências Agrárias e da Biodiversidade - CCAB, da Universidade Federal do Cariri (UFCA) localizado no Campus Crato pertencente ao município de Crato-CE, com as seguintes coordenadas geográficas: 71ㄴ'1.3”S, 3922'9.3”W, a 454 metros de altitude.

Segundo Köeppen, o clima da região é classificado como 'Aw', tropical úmido, com inverno característico seco, com chuvas observadas de novembro a abril e estação seca no inverno de maio a outubro. 
As precipitações pluviométricas são geralmente superiores a $750 \mathrm{~mm}$ anuais.

Foi utilizado o delineamento experimental inteiramente casualizado - DIC, em esquema fatorial $4 \times 5$, com quatro repetições. O primeiro fator foram as 4 cultivares de gergelim (BRS Seda, Embrapa, cultivar de Barros e Cultivar de Milagres) e o segundo fator foram as 5 proporções de substrato a base de esterco bovino (EB) e solo (S): $100 \%$ solo, $25 \%$ EB $+75 \%$ solo, $50 \%$ EB $+50 \%$ solo, $75 \%$ EB $+25 \%$ solo e $100 \%$ EB.

Utilizaram-se bandejas de isopor com 128 células como recipientes para avaliação experimental. Essas bandejas receberam os substratos distribuídos conforme sua proporção. O solo usado na mistura do substrato foi o Latossolo Amarelo distrófico. A semeadura de todas as cultivares foi efetuada com três sementes por célula, e um total de oito células por parcela, totalizando vinte e quatro sementes por tratamento. A irrigação foi feita diariamente com irrigador convencional, distribuindo iguais quantidades de água para todos os tratamentos.

Foi realizada a contagem de plantas emergidas em intervalos de $24 \mathrm{~h}$ até o final da emergência. As variáveis analisadas foram o Índice de emergência inicial (In.EI), Índice de emergência final (In.EF), porcentagem de emergência inicial (\%EI), porcentagem de emergência final (\%EF), número de dias para estabilizar a emergência (NDE) e Índice de velocidade de emergência (IVE).

O índice de emergência inicial foi obtido pela média aritmética da emergência dos primeiros sete dias: $E 1+E 2 \ldots+E 7 / 7$. O índice de emergência final foi calculado pela média aritmética das emergências observadas entre o oitavo e o término de todas as emergências (décimo quinto dia): E8+E9...+E15/7. A porcentagem de emergência inicial foi estabelecida pela média da emergência, multiplicado por 100, no primeiro período (7 dias): \%El= E1+E2 ...+E7/7×100. A porcentagem de emergência final foi obtida através da equação: \%EF=E8+E9...+E15/7×100. O NDE foi considerado o último dia que foi observada a emergência de plantas na parcela, no período de 15 dias. $O$ índice de velocidade de emergência foi determinado através da equação: IVE= N1/1+N2/2...+N15/15, sendo o denominador considerado como o dia da análise. Os maiores valores para IVE constituem maiores velocidades de emergência.

Os dados foram submetidos à análise de variância para avaliar os efeitos significativo, por meio do teste de comparação de médias Tukey a $F(p \leq 0,01)$ e $F(p \leq 0,05)$ de probabilidade para o fator qualitativo. Os dados quantitativos foram testados por regressão, escolhendo-se o modelo com maior coeficiente de determinação $\left(R^{2}\right)$, empregando o programa SISVAR.

\section{RESULTADOS E DISCUSSÃO}

Para as variáveis IVE, NDE, \%EF, \%EI e In.EF, (Tabela 1) o coeficiente de variação foi considerado médio, demonstrando uma variação intermediária (10-20). Segundo Pimentel-Gomes (2009), o grau do coeficiente de variação pode ser considerado como baixo, médio e alto, de acordo com os valores obtidos na ANOVA, de seguinte maneira: baixo $(<10)$, médio (10-20) e alto (20-30). Já para o Índice de emergência inicial, $(C V>20)$, nota-se alta dispersão dos dados, indicando que houve interação significativa entre cultivar e substrato, denotando um comportamento diferente das cultivares em função do substrato. 
A cultivar crioula de Barros expressou-se maior In.EF, \%EI, \%EF e IVE em relação às demais. No entanto, não diferiu significativamente da cultivar BRS-Seda quando se analisou o fator NDE. Sementes de alto vigor apresentam maior velocidade nos processos metabólicos, propiciando emissão mais rápida e uniforme da raiz primária no processo de germinação e maior taxa de crescimento (CARNEIRO et al., 2020). Estima-se que esse comportamento é observado porque, ao longo dos anos, essa cultivar adaptou-se de modo natural às condições climáticas locais, característica não observada na maioria das cultivares melhoradas, uma vez que essas recebem ótimas condições para desenvolvimento, reduzindo o vigor quando submetidas à diferentes situações de solo, clima, umidade e adubação, por exemplo.

Tabela 1: Síntese da análise de variância para o Índice de emergência inicial (In.EI), Índice de emergência final (In.EF), porcentagem de emergência inicial (\%EI), porcentagem de emergência final (\%EF), número de dias para emergência (NDE) e Índice de velocidade de emergência (IVE).

\begin{tabular}{|c|c|c|c|c|c|c|}
\hline \multirow[t]{2}{*}{ Fatores } & \multicolumn{6}{|c|}{ Quadrados médios } \\
\hline & In. El & In. EF & $\% \mathrm{El}$ & $\% \mathrm{EF}$ & NDE & IVE \\
\hline Cultivar(C) & $75,79 * *$ & $18,58 * *$ & $137,27^{* *}$ & $35,07 * *$ & $15,84^{* *}$ & $7,35 * *$ \\
\hline Substrato(S) & $39,18 * *$ & $10,96 * *$ & $86,08 * *$ & $20,98 * *$ & $79,38 * *$ & $6,12 * *$ \\
\hline $\mathrm{CXS}$ & $2,91^{*}$ & $0,94^{\mathrm{ns}}$ & $6,7^{\mathrm{ns}}$ & $180,04^{\text {ns }}$ & $110,5^{\text {ns }}$ & $1,2^{\mathrm{ns}}$ \\
\hline Cv\% & 22,17 & 13,4 & 15,51 & 17,21 & 13,28 & 11,89 \\
\hline
\end{tabular}

${ }^{1}$ Os dados do desdobramento da interação estão apresentados nas figuras $\mathrm{x} \mathrm{e} y .{ }^{* *}$ : significativo $(\mathrm{P}<0,01) ;{ }^{*}$ : significativo $(\mathrm{P}<0,05)$; ns: não significativo; CV\%: coeficiente de variação.

Verifica-se significância entre as cultivares dentro de todos os níveis de substrato a $1 \%$ de significância pelo teste de Tukey. Ao se aplicar a análise de variância para níveis quantitativos de substrato, verificou-se o comportamento de cada cultivar dentro de cada fator.

A cultivar melhorada da Embrapa respondeu positivamente ao nível 0\%, não diferindo da cultivar crioula de Barros e se sobressaindo em relação as cultivares BRS-Seda e crioula Milagres (Figura 1). A 25\% e 75\% de substrato, a cultivar crioula Barros teve maior rendimento, obtendo melhores valores de emergência. A cultivar crioula de Milagre, teve pior desempenho quando testada a $25 \%$ de esterco e, em relação a $75 \%$, não diferiu das cultivares BRS-Seda e Embrapa. Na porcentagem 1:1 (50\%), a cultivar crioula Barros permaneceu estatisticamente equivalente a cultivar BRS-Seda e Embrapa e a pior foi a crioula Milagres. Em 100\% de esterco bovino, a cultivar crioula Barros e cultivar da Embrapa não apresenta diferença entre si, assim como as cultivares crioula Milagre e BRS-Seda também não diferem.

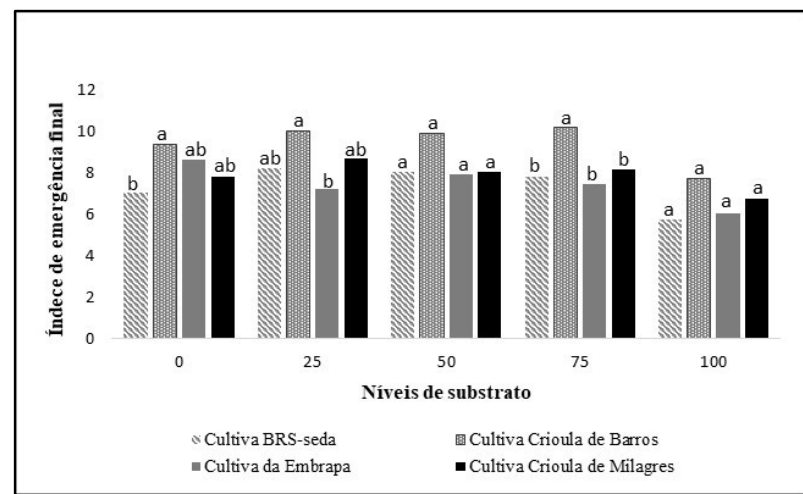

Figura 1: Índice de emergência final de quatro cultivares de gergelim.

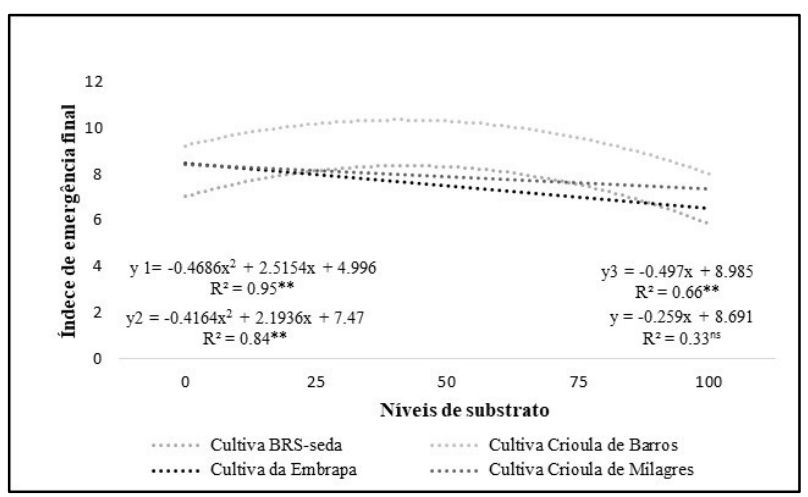

Figura 2: Desdobramento da ANOVA para índice de emergência final de quatro cultivares de gergelim em diferentes níveis de substrato. 
As cultivares Crioula Barros e BRS-Seda se comportaram de forma polinomial, tendo o pico de emergência em nível 50\% de esterco; a partir desse ponto houve menores índices de emergência final (Figura 2). As cultivares Embrapa e crioula Milagres apresentaram-se de forma linear, decrescendo conforme o aumento do nível de substrato; verificou-se maior In.FE em $0 \%$ de substrato.

A cultivar crioula Barros foi a mais precoce no quesito germinação sob os níveis $25 \%$ e $75 \%$, diferindo estatisticamente de todas as outras. Sob $0 \%$ de esterco, a cultivar Barros não diferiu significativamente da cultivar Embrapa, sendo diferente das demais (Figura 3). Quando colocada em 50\% de esterco, a pior cultivar foi a crioula Milagres; entre as demais não se observou diferença. A cultivar crioula Barros é mais precoce em emergência em substrato contendo $100 \%$ de esterco quando comparada com as cultivares BRS-Seda e crioula Milagres, sendo equivalente a cultivar Embrapa.

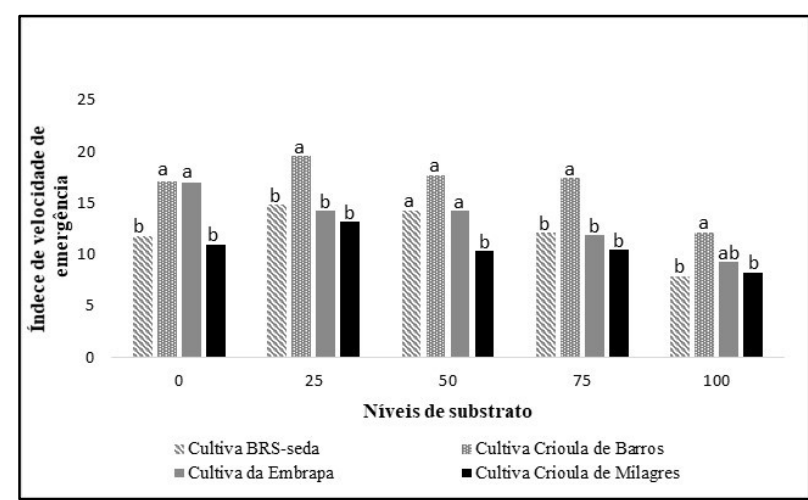

Figura 3: Índice de velocidade de emergência de quatro cultivares de gergelim em diferentes níveis de substrato.

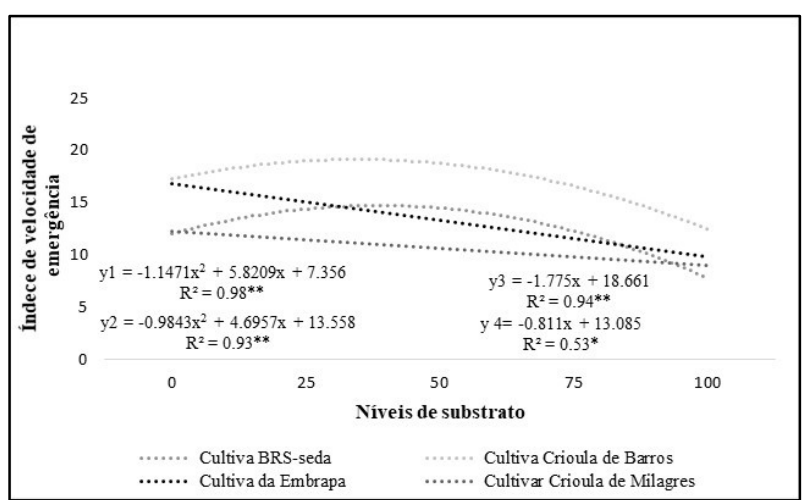

Figura 4: Desdobramento da ANOVA para índice de velocidade de emergência de quatro cultivares de gergelim em diferentes níveis de substrato.

As cultivares crioula Barros e BRS-Seda se comportaram de forma quadrática, emergindo com maior velocidade em nível 25\% de esterco, havendo menor IVE com maiores concentrações de esterco (Figura 4). As cultivares Embrapa e crioula Milagres mostraram-se de forma linear, decrescendo de acordo com o aumento da proporção de substrato.

Se tratando de emergência inicial, em nível 0\% de esterco, as cultivares Barros e Embrapa foram as melhores, sendo equivalentes entre si, diferindo das cultivares BRS-Seda e Milagres (Figura 5). Em 25\%, a cultivar Barros se sobressaiu sobre a cultivar Embrapa, mas não diferiu das cultivares BRS-Seda e crioula Milagres. No substrato com presença de $50 \%$ de composto orgânico, a cultivar crioula Barros foi a melhor, porém não se mostrou diferente da cultivar BRS-Seda; as demais foram equivalentes, sendo as piores nesse quesito. Em 75\%, a cultivar Barros foi a melhor, diferindo de todas as outras, indicando maior resistência à umidade. Novamente, sob 100\% de esterco, as cultivares Barros e Embrapa não diferiram entre si, sendo as melhores. Porém, a mesma diferiu das cultivares BRS-Seda e crioula Milagres, classificando as últimas como as piores dentro dessa análise de \%EI.

O comportamento das cultivares BRS-Seda, crioulas Barros e Milagresfoi observado de forma polinomial de segunda ordem, denotando que a melhor porcentagem de emergência ocorreu quando as sementes foram submetidas a $46 \%$ de esterco; proporções maiores ou menores proporcionaram queda no 
aspecto El\% (Figura 6). Observou-se curva de tendência linear para a cultivar Embrapa, mostrando a queda dessa com o aumento da quantidade de esterco.

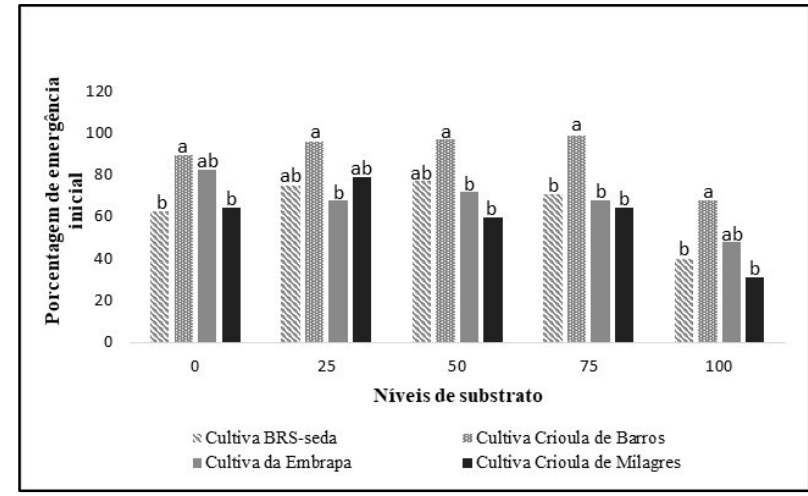

Figura 5: Porcentagem de emergência inicial de quatro cultivares de gergelim em diferentes níveis de substrato.

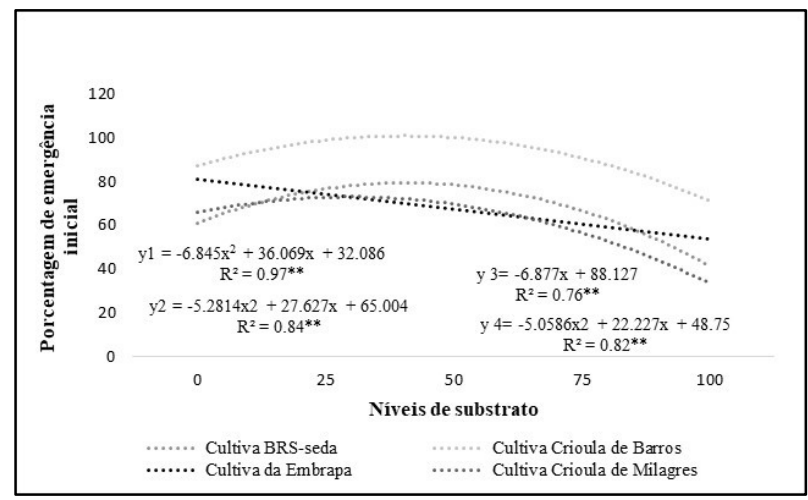

Figura 6: Desdobramento da ANOVA para porcentagem de emergência inicial de quatro cultivares de gergelim em diferentes níveis de substrato.

Dentro das porcentagens 50\% e 100\% não se observou diferenças entre as cultivares testadas (Figura 7). Sem a presença de esterco (0\%), a cultivar crioula Barros foi a melhor, não diferindo das cultivares Embrapa e Milagres, mas quando comparada com a cultivar BRS-Seda, houve diferença significativa. Em substrato com proporção $25 \%$, a cultivar Barros se sobressaiu, sendo estatisticamente equivalente as cultivares BRS-Seda e Milagres. A cultivar Embrapa foi a pior. De acordo com Cruz et al. (2019) o gergelim é extremamente susceptível ao encharcamento e com chuvas intensas e contínuas, o crescimento das plantas é paralisado e, caso sejam mais frequentes e contínuas, podem levar as plantas à morte, com o surgimento de diversas doenças. Em relação à umidade, a cultivar Barros submetida a substrato contendo $75 \%$ de esterco, diferiu significativamente das cultivares BRS-Seda e Embrapa, mas não foi diferente significativamente da cultivar Milagres, suportando maiores quantidades de umidade, uma vez que o esterco retém boa quantidade de água.

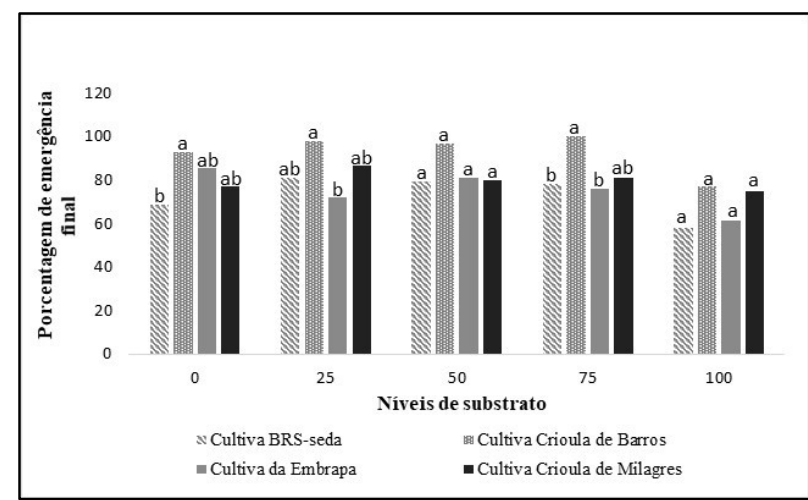

Figura 7: Porcentagem de emergência final de quatro cultivares de gergelim em diferentes níveis de substrato.

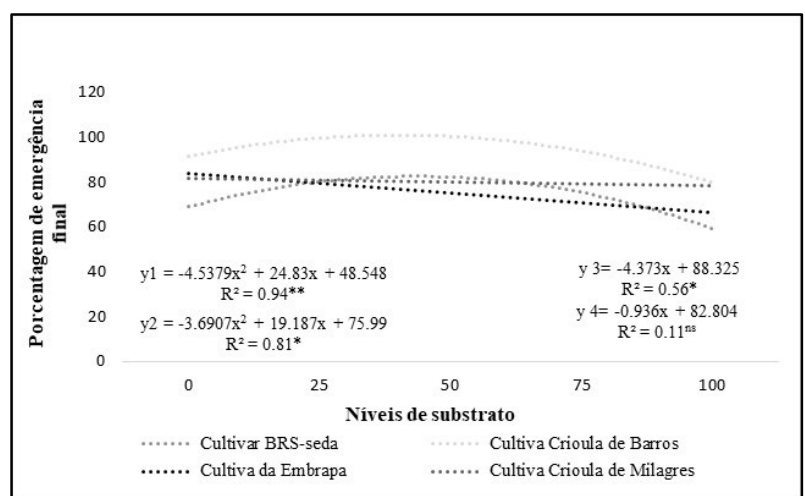

Figura 8: Desdobramento da ANOVA para porcentagem de emergência final de quatro cultivares de gergelim em diferentes níveis de substrato.

As cultivares Barros e BRS-Seda se expressaram de forma polinomial, tendo melhores valores de emergência final quando submetidas a aproximadamente $44 \%$ de esterco; valores maiores ou menores taxam resultados menos positivos na emergência final (Figura 8). As cultivares Embrapa e Milagres, de modo 
geral, são mais sensíveis à adubação orgânica, decrescendo conforme em função do aumento na proporção de esterco.

Não houve diferença significativa entre as cultivares sob níveis $0 \%, 25 \%$ e $75 \%$, tornando-as iguais quando analisada a tendência das cultivares ser ou não rápidas na emergência (figura 9). Em 50\%, a mais precoce na emergência foi a cultivar crioula Barros que foi equivalente a cultivar BRS-Seda. As mais tardias foram as cultivares Embrapa e crioula Milagres. Na análise do substrato contendo 75\% de esterco, a cultivar crioula Barros diferiu da cultivar Embrapa, mas não foi diferente das cultivares BRS-Seda e Milagres.

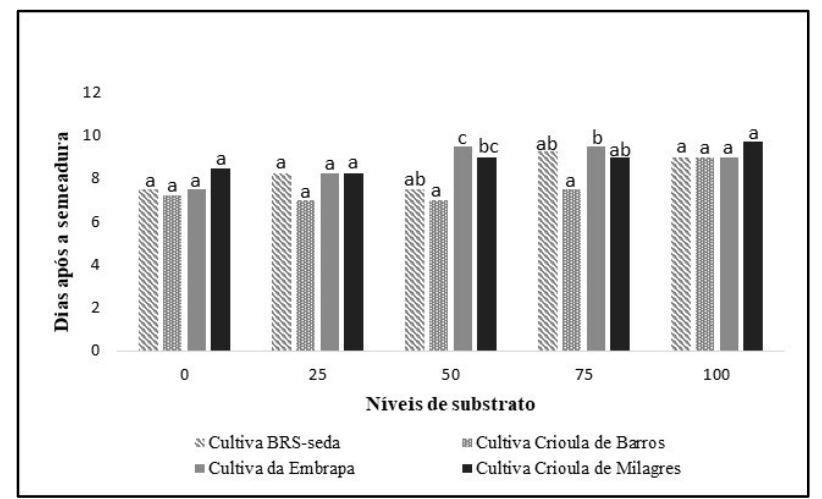

Figura 9: Número de dias de emergência após a semeadura de quatro cultivares de gergelim em diferentes níveis de substrato.

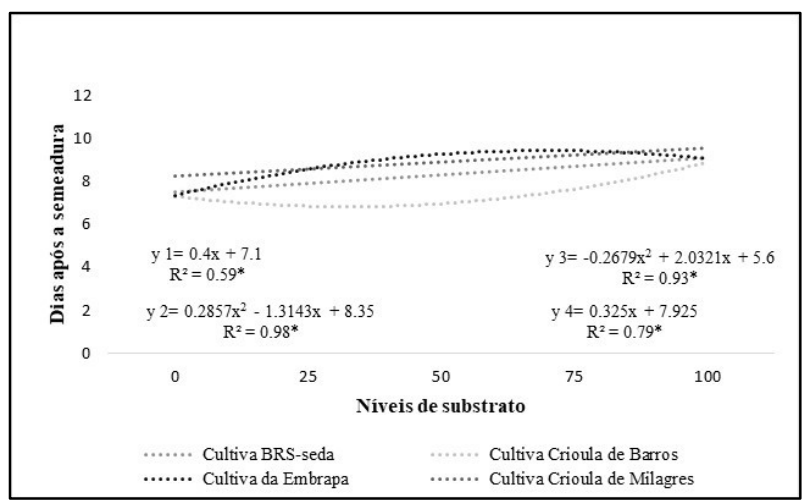

Figura 10: Desdobramento da ANOVA para dias após a semeadura de quatro cultivares de gergelim em diferentes níveis de substrato.

Observa-se curva de tendência polinomial para as cultivares crioula Barros e Embrapa (Figura 10). A cultivar crioula Barros foi a mais precoce em nível 50\% de substrato. As cultivares BRS-Seda e crioula Milagres se comportaram linearmente, ficando mais tardias com o aumento nos níveis de esterco.

Nas porcentagens $25 \%$ e $75 \%$, a cultivar Barros foi a melhor comparada com as demais (Figura 11). Em 0\% foi significativamente igual a cultivar Embrapa, diferindo das demais. No substrato com $50 \%$ a pior cultivar analisada foi a crioula Milagres, diferindo das demais. Com 100\% de esterco a cultivar Barros se expressou de forma significativa, diferindo das cultivares BRS-Seda e Milagres que foram as piores.

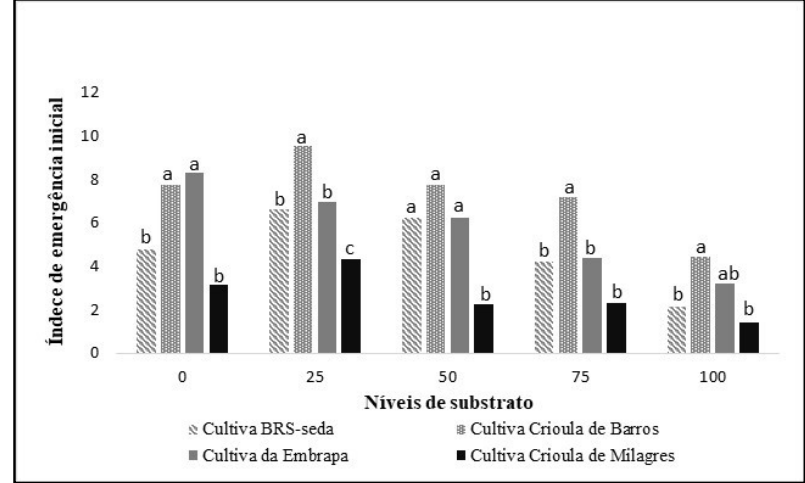

Figura 11: Índice de emergência inicial de quatro cultivares de gergelim em diferentes níveis de substrato.

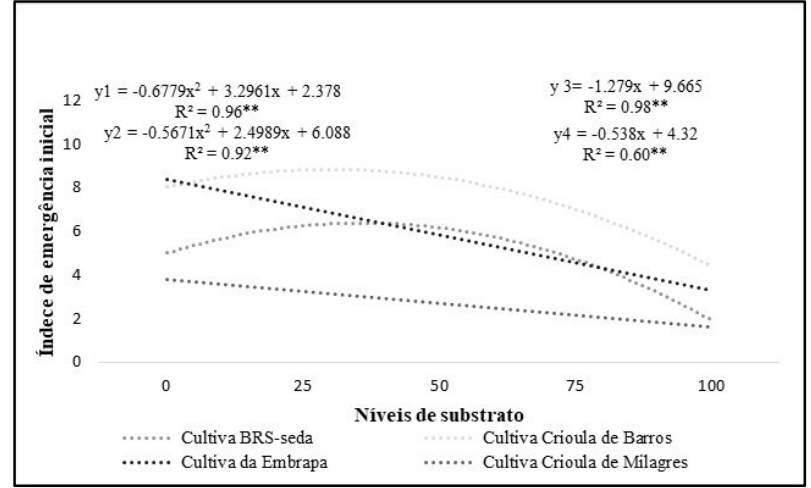

Figura 12: Desdobramento da ANOVA para índice de emergência inicial de quatro cultivares de gergelim em diferentes níveis de substrato.

A cultivar crioula Barros se mostrou com curva de tendência polinomial e pico de emergência em nível $25 \%$, havendo menores valores com a diminuição ou o aumento do nível de substrato. As cultivares 
Embrapa e Milagres foram descritas pelo modelo linear, tendo a emergência reduzida com o aumento do nível de esterco. A cultivar BRS-Seda foi descrita pelo modelo polinomial com pico de El em nível 50\% de esterco.

\section{CONCLUSÕES}

A cultivar Crioula de Barros apresentou maior eficiência nos quesitos analisados: IVE, NDE, \%EF, \%El, In.EF e In. El, conferindo maior viabilidade aos produtores. As cultivares melhoradas obtiveram menores rendimentos quando submetidas em substratos contendo $0 \%$ e $100 \%$ de esterco.

\section{REFERÊNCIAS}

CARNeIRo, T. H. M.; CAVALCANTE, A. G.; CAVAlCANTE, A. C. P.; ANDRADE, G. A. V.; LIMA, N. J. C.; AQUINO, L. A.. Efeito do vigor de sementes sobre as características fisiológicas e produtivas da soja. Acta Iguazu, v.9, n.2, p.122-133, 2020.

CARVALHO, J. B.; MOTA, J. M. N.; ALVARENGA, C. B.; MACIEL, G. M.; SILVA, A. D.; BORBA, M. E. A.. Produção e qualidade fisiológica de sementes de alface cultivada com adubação orgânica e mineral. Revista de Ciências Agrárias Amazonian Journal of Agricultural and Environmental Sciences, v.60, n.1, p.70-76, 2017. DOI: http://dx.doi.org/10.4322/rca.2424

CRUZ, N. F. F. S.; NASCIMENTO, L. F. J.; SANTOS, R. F.; JÚNIOR, L. A. Z.; CUNHA, E.; ROCHA, E. O.. Características e tratos culturais do gergelim (Sesamum indicum L.). Revista Brasileira de Energias Renováveis, v.8, n.4, p.665-675, 2019. DOI: https://10.5380/rber.v8i4.65757

DIAS, A. S.; LIMA, G. S. D.; GHEYI, H. R.; NOBRE, R. G.; SANTOS, J. B. D.. Emergência, crescimento e produção de gergelim sob estresse salino e proporções de nitrato e amônio. Revista Caatinga, v.30, n.2, p.458-467, 2017. DOI: https://10.1590/1983-21252017v30n221rc
FURTADO, G. F.; SOUZA, A. S.; LACERDA, R. R. A.; CHAVES, L. H. G.; SOUSA JÚNIOR, J. R.; SOUSA, J. R. M.. Produção de feijão-caupi e gergelim consorciado com mamoneira no Semiárido paraibano. Revista Verde de Agroecologia e Desenvolvimento Sustentável, v.12, n.1, p.1-6, 2017. DOI: https://10.18378/rvads.v12i1.4890

NÓBREGA, J. S.; NASCIMENTO, L. C.. Sanidade de sementes e sua influência no controle de fitopatógenos. Research, Society and Development, v.9, n.10, p.e649108101e649108101, 2020. DOI: https://10.33448/rsd-v9i10.8101

PIMENTEL-GOMES, F.. Curso de estatística experimental. 15 ed. Piracicaba: Fealq, 2009.

SILVA, R. T. D.; OLIVEIRA, A. B. D.; LOPES, M. D. F. D. Q.; GUIMARÃES, M. D. A.; DUTRA, A. S.. Qualidade fisiológica de sementes de gergelim produzidas a partir de plantas submetidas ao estresse hídrico. Revista Ciência Agronômica, v.47, n.4, p.643-648, 2016. DOI: https://doi.org/10.5935/1806-6690.20160077

SOUSA, G. G.; VIANA, T. V. A.; DIAS, C. N.; SILVA, G. L.; AZEVEDO, B. M.. Lâminas de irrigação para cultura do gergelim com biofertilizante bovino. Magistra, v.26, n.3, p.343-352, 2017.

A CBPC - Companhia Brasileira de Produção Científica (CNPJ: 11.221.422/0001-03) detém os direitos materiais desta publicação. Os direitos referem-se à publicação do trabalho em qualquer parte do mundo, incluindo os direitos às renovações, expansões e disseminações da contribuição, bem como outros direitos subsidiários. Todos os trabalhos publicados eletronicamente poderão posteriormente ser publicados em coletâneas impressas sob coordenação da Sustenere Publishing, da Companhia Brasileira de Produção Científica e seus parceiros autorizados. Os (as) autores (as) preservam os direitos autorais, mas não têm permissão para a publicação da contribuição em outro meio, impresso ou digital, em português ou em tradução. 